\title{
Woman in Either/Or, I \& II: A Computer Analysis
}

Alastair McKinnon

Officially Either/Or opposes the aesthetic and the ethical view of life and consists of the writings of the Young Man or A (vol. I) and the reply by Judge William or B (vol. II), all found by accident in a secret compartment of a second hand secretary by Victor Eremita who writes that he merely agreed to act as their editor. In fact, of course, it was written by Kierkegaard between October 1841 and November $1842^{1}$ in Berlin following his flight from Copenhagen after he had broken his engagement to Regine and is really a love letter explaining his action. I mention this not to encourage the easy game of discounting its message as due to these circumstances but rather to try to prepare you for the quite fantastic insights into the erotic life and the real nature of woman found in this work and to remind you that, even as its second reader, you also must make a choice.

I have been asked to do a study of woman in these two volumes. At first glance this seems a strange request because these books present and celebrate the aesthetic and the ethical views of life and appear to deal only indirectly and in passing with the nature of woman. At the same time it is also very plausible because both A and B articulate their respective life views mainly in terms of their relation to and concept of woman. Put another way, these volumes are not about woman and yet she is obviously central to them. This paradox constitutes at least part of the challenge of this paper.

1 Cappelørn, Niels Jørgen and McKinnon, Alastair, "The Period of Composition of Kierkegaard's Published Works," Kierkegaardiana, 1974. 
Of course those familiar with my recent work may suspect that I also have another agenda. Over the years I have become increasingly distressed by the state of literary studies and particularly sceptical about our ability to do significantly better using either traditional or current approaches. As a philosopher I have become increasingly convinced that we see and, indeed, can see only what we are looking for, that the most important facts are those which do not fit our theories and which we therefore cannot see and that every interpretation of text is necessarily and in principle a misinterpretation. I believe that Luis Borques' "Pierre Mésnard" is one of the truly profound stories of our time and that if Kant could have written The Critique of Pure Reason more briefly or simply, he would and should have done so. In short, no comment can possibly be fair comment and the best the tradition can offer is the time honoured practice of cheating by quotation. I can, therefore, understand why current French theorists have decided that a text means nothing at all or anything one wants it to mean but this is only a cheap cop-out born of a preference for the ease of the café to the honest work of the study. Burdened with these convictions, I have been driven to radical views of the nature of text and of the right road for literary studies. I believe that we have been taken in by the technology of print, that the real book is the vision in the mind of the author which he is seeking to convey to the reader through the medium of the printed text, that this vision literally "enforms" that text and can be reconstructed from the distribution patterns of the words which are central to it and that the goal of literary studies should be the re-creation and exploration of this "space." In many recent studies I have attempted to map the space of Kierkegaard's authorship and some of his books and concepts, and in the present one I attempt to recreate and explore the "space" of A's and B's concept of woman. Before I am finished you may well conclude that the price is too high but, 
given my convictions, I cannot see that I have any other choice.

The method used in this study can be described in wholly general terms. Extract from the text all instances of the most appropriate context unit, sentences for example, containing one or more occurrences of all relevant forms of the search word. Count all the words in this extracted text. Identify all words occurring in this text and hence co-occurring with the search word with an excessive or aberrant frequency. Divide the original extracted text file into sections corresponding to the divisions of the original printed text. Count all the words in each of these divisions. Create a matrix showing the frequency of each aberrant frequency word in each division of the text. Do a correspondence analysis of this matrix in order to identify the dimensions and map the "space" of the book or concept in question. Finally, think long and hard about the many and varied results produced by the program!

Of course one must adapt any such general method to particular cases and make choices appropriate thereto. In this study I have used as my "search words" the 10 main forms of "woman": Qvinde [woman], Qvinden [the woman]. Qvindens [the woman's], Qvinder [women], Qvindes [woman's], qvindelig and qvindelige [womanly], Qvindelighed [womanliness or femininity], Qvindeligheden [the womanliness], and Qvindelighedens [of the womanliness]. In most previous studies I have used the sentence as the context unit and believe I have shown that it is generally the best such unit, but there are only 96 occurrences of all forms of the above search words in each of our texts and, of course, fewer sentences. Further, those in EE $1^{2}$ are

\footnotetext{
2 As in The Nierkegaard Indices I use EE1 to refer to Enten Eller (Forste Deel) and its various translations and EE2 to refer to Enten Eller (Anden Deel) and its various translations. Note that the ver few passages quoted in this study are from the older SWENSON-LOWRIE translation revised by
} 
the shortest in the entire authorship. ${ }^{3}$ I therefore concluded that the sentence would probably not yield enough extracted text for statistically reliable results and that the paragraph was in any event more in keeping with the complex relation of woman to the subject of these volumes already mentioned and extracted all paragraphs in each volume containing one or more occurrences of any of the search words already noted. For the aberrant frequency word test I compared the frequency of every word in all the 'woman' paragraphs of each volume with the frequency of the same word in Kierkegaard's entire authorship and set the minimum frequency at 4 and the minimum $\mathrm{Z}$ score at 2.58 standard deviations, settings which gave 236 aberrant frequency words for EE1 and 161 for EE2. Note that this means that every one of these words occurs in the 'woman' paragraphs of the volume in question four or more times and that the probability of its doing so in a text of that length by Kierkegaard is less than one in 100. In fact most words in this study have a much higher $\mathrm{Z}$ score and a probability much less than one in 100,000; for example, the 94 occurrences of "Don" (as in Don Juan) in the 'woman' paragraphs of EE1 represent a Z score of 40.45 and a probability of less than one in many million, and this word is therefore clearly and closely linked with woman in the "mind" or "vision" of the author of this work. ${ }^{4}$ Ordinarily one divides

HowARD A. JOHNSON, that this is mainly because readers are now more familiar with the new HONG AND HoNG translation and that in all cases I cite page numbers in the Danish third edition, the SWENSON-LOWRIE and the HONG AND HONG translation in that order. Thus in the case of EEI, for example. the reference $396 / 424 / 429$ means that the text in question can be found on p. 396 of the Danish third edition and on p. 424 of the SWENSONLOW'RIE and p. 429 of the HONG AND HONG translation.

${ }^{3}$ The average sentence length for EE1 is 23.40 , that for EE2 30.23 and that for the corpus as a whole 30.47 .

${ }^{4}$ It may seem ridiculous to note this connection but the computer knows 
extracted texts according to the divisions of the original, but this proved impracticable in both of the present cases. The "Preface" and "Diapsalmata" of EE1 together contain only two occurrences of our search words and have been combined into a single unit henceforth identified as PD. Neither "The Unhappiest Man" nor, strangely, "The First Love" contain a single such occurrence and "The Rotation Method" presents woman simply as an alternative to boredom and so in a way quite inconsistent with the rest of this book. ${ }^{5}$ This left only "The Immediate Stages of the Erotic or the Musical Erotic," "The Ancient Tragical Motif as Reflected in the Modern," "Shadowgraphs" 6 and "Diary of the Seducer" henceforth identified as ME, TR, SH and DS, respectively. ${ }^{7}$ The problem with EE2 was somewhat different. This volume contains only three parts the last of which, the "Ultimatum," makes no mention of woman. By contrast, both the "Aesthetic Validity of Marriage" and the "Equilibrium between the Aesthetical and the Ethical in the Composition of Personality" have many paragraphs containing some form of

nothing about it and deduced it from the frequency of this word in the paragraphs in question: in fact it uses exactly the same procedure to identify many other such connections which no one would ever suspect or imagine.

${ }^{5}$ This may be a slight exaggeration since the other divisions of the text perhaps assume such a conception as well. However "The Rotation Method" constantly uses various forms of the verb "to bore" in connection with woman and their inclusion so distorts the space of this concept as to render it illegible and unusable. This at least suggests that boredom may not be as central to the whole of EEI as is generally supposed.

6 The Hoxgs' translation of this title as "Silhouettes" is much better for many reasons but. having used the other SwENSON-Low'RIE titles. I felt bound to use this one.

${ }^{7}$ The "woman' paragraphs in these five divisions of EEl occur in that text as follows: PD 16-36/11-33/xiii-34: ME 57-124/56-132/58-133: TR 141147/151-157/153-159: SH 159-188/169-202/171-203: and DY 266-410/284$4+4 / 288-4+5$. 
"woman" and I have therefore divided those from the former into M1, M2, M3, and M4 and those from the latter into E1 and E2. ${ }^{8}$ Thus the matrix for "woman" in EE1 shows the frequencies of 236 words in each of five sections and that for this same word in EE2 those of 161 words in each of our six divisions of that text. Much of the rest of this study is a detailed examination of the results of a correspondence analysis ${ }^{9}$ of these two matrices. Too briefly, that program arrays all row or word and all column or book points in two separate multi-dimensional spaces on the basis of the similarity of their "profiles," collapses these two spaces into a new true multi-dimensional space and reports the co-ordinates, contributions and correlations of each point on each dimension. Both these matrices and these results contain a great deal of valuable information but unfortunately are much too large for inclusion in this study.

The first and perhaps most readily intelligible results of this study are the aberrant frequency word lists for the two accounts of woman in question. These are given in table 1 not in their original but rather in a 'compare' format which arrays them in three columns with those unique to A's account in the first, those common to both in the second and those unique to B's in the third. Note that the presence of a word in the first or third column is a clue to what is distinctive in that concept while its absence may mean only that it was not used sufficiently often to

${ }^{8}$ The 'woman' paragraphs in these six divisions of EE2 occur within the following pages of that work: M1 14-29/9-25/9-25; M2 52-74/51-76/50-75; M3 80-93/83-98/82-96; M4 108-112/115-119/113-117; E1 174-194/190213/185-209; and E2 281-300/311-332/306-326.

9 Correspondence analysis is a powerful and relatively new statistical technique which arrays the row and column points of a frequency matrix in multi-dimensional space on the basis of their "profiles." Briefly, it clusters those having similar profiles and disperses those having different ones. I use and recommend MiCHAEL J. GREENACRE'S SimCA 2.0. 
meet the criteria specified above. Note too that these words are shown in English but, apart from the Greek Symparanekromenoi, ordered according to the Danish alphabet and that we cite the original Danish only when this is necessary to making the significance of the word quite clear. Finally, note that every one of these many words plays a significant role in and is an important clue to the nature of the concept in question. For example, that of A's six uses of "opposition" or "resistance" $[$ Modstand] is clear from his revealing remark "...woman's nature is submission in the form of resistance." $(359 / 384 / 356)^{10}$ Note, however, that it is equally true of B's 10 uses of "A" or "An" $[E t]$ and indeed of his aberrantly frequent uses of other neuter articles and pronouns such as Dit, Et, et, mit which show beyond possible doubt that his account of woman contains a much higher proportion of neuter nouns than A's or, for the matter, Kierkegaard's writings as a whole. I confess that I cannot for the moment explain this remarkable phenomenon but, if the Danish distinction between neuter and common nouns has any meaning, it :s clearly of great importance and deserves the careful attention of some literary scholar-cum-psychiatrist. Of course, traditional scholarship rarely if ever notes such obscure and humble features of a text, but it is clear that they convey important information and should be taken seriously.

Perhaps the clearest and most striking of these results is that contained in the statistical summary at its end. This shows that there are 205 words unique to A's account, 130 unique to B's and 31 common to both and that these lists have only $8.47 \%$ of their words in common or, a more appropriate measure for lists of such different lengths, an index of concordance of only 0.124 . I do not have great confidence in our ability to use the words

10 This reminds one of the now famous Quebec judge who announced in court that woman was like the law in that she was made to be violated. 
"same" and "different", but this is one of the lowest indices I have ever seen and, given the fact that they are about the same subject, are clear evidence that these two lists and, hence the concepts they reflect and in some sense summarize, are indeed very different.

The following is a very brief account of some of the more interesting and important differences between these two lists. Both include "woman," "the woman" and "the woman's" but only A shows "womanly" (sing. and pl.), "womanliness," "of womanliness" and "woman's" and only B "women." Further, and with their $\mathrm{Z}$ scores to provide a rough indication of their relative importance, only A shows "virginity" [.Jomfruelighed $]$ " (26.10), "girl" (18.99), "young" [ung] (15.96), "bride" (7.00), "girls" (5.66), "girl's" (4.10), "young" [unge] (3.15) and six celebrated female figures [Cordelia, Antigone, Diana, Elvira, Elvire and Zerline ] while only B shows "wife" or "woman" [Kone] (18.80), "marriage" (12.41), "the marriage" (12.17) "the men" (10.10), "marries" (8.08), "home" (6.92), "child" (6.41), "children" (4.93), "wife" [Hustru] $]^{12}$ (4.93), "the children" (4.71), "mother" (4.41), "man" (3.78), "men" (3.75), "to marry" (3.51), "marry" (imp.) (3.65) and "husband" 2.91 A typically refers to "bosom" as Barm (10.73) and B as Bryst

11 This word is occasionally and correctly rendered "girlishness" and even "foolishness" in SWENSON-LOWRIE. The new HONG AND HONG translation seems always to render it as "virginity" but the qualification "pure" suggests that A sometimes has some special sense in mind.

12 In a draft of EE2 Kicrkegaard expressly coments upon the importance of this particular word. Having emphasised that it is the woman who forms the home, he continues "This is also beautifully expressed in the word "wife" [Hustru], i.e. faithfulness in the house, a house where faithfulness dwells, or a faithfulness in which love finds its home. Such an expression. so simple and plain and yet so rich in blessing. romantic love does not have." Quoted from Either Or. II, trs. by HOW ARD V. HONG AND EDNA H. HONG. Princeton University Press. p. 375. 
(5.49). In a curious but interesting reversal of their basic positions, A stresses that woman is "stronger" [starkere] (3.06) and B that she is "weak" [svag] (4.05). A favours Veemod (4.23) for "melancholy" but B the more usual Tungsind (3.25). A writes of "moments" [Momenter] (4.57) and "the moment" [Momentet] (7.05) but B of "instant" or "moment" [Øieblik] (2.88) and "instants" or "moments" [Oieblikke] (3.25). A expresses "Now" as $N u(2.71)$ while B, replying to A, expresses his "now" as snart (2.85), as in "...now you enjoy in a manly way, now in a womanly; now you enjoy immediately, now you enjoy ..." (28/25/24). A declares that woman is "being for another" [Andet Varen] (3.70 and 14.85) while B affirms her autonomy by insisting that she is "a being" [Vosen] (6.68). A favours the verb forms "enjoys" [attraaer] (6.16), "enjoyed" [attraaet] (17.20) and "enjoys" [nyder] (3.22) but B the noun "enjoyment" [Nydelse] (5.17). A makes frequent use of the passive "is born" [fødes] (5.43) as in "...A young girl takes a long time in being born [fødes], and is born [fødes] full-grown." (307/327/332) while B favours the active "to give birth to" [føde] as when he tells A that he is "like a woman who imagines she might give birth to a monster." (192/210/206) A's list contains "feels" [foler] (6.18) but B's only the noun "feeling" [Folelse] (5.09). A writes of a "secret" [Hemmelighed] (5.72) but B instead of "secrets" [Hemmeligheder] (7.39). The A list includes both "nature" [Natur] (3.98) and "the nature" [Naturen] (4.37) but the B list only the definite genitive "nature's" [Naturens] (4.97) as in his reference to man and woman's quite different relations to the magnificence and splendor of nature. (285/315/278) Finally, a difference which reflects their quite different literary styles. No doubt indulging his taste for mere difference and variety, A tends to begin sentences with "Not" [Ikke] (4.60), "Although" [Skjøndt] (4.49), "And yet" [Endnu] (4.44), "As" [Idet] (3.56), "More" [Mere] (3.33), 
"With" [Med] (2.98), "Hence" or "Therefore" [Derfor] (2.97), "This" [Denne] (2.97), "In the case of" [Imidlertid] (2.93), "Also" [Ogsaa $]$ (2.87) and "Now" [Nu] (2.71) while the more sober B tends instead to do so with "Hence" or "Besides" [Dertil] (5.63), "A" or "An" [Et] (3.98) and "Think" [Tienk, imp.] (3.97). Of course there are many other differences between these lists and the reader is invited to identify and explore these for him- or herself. That said, I now attempt to name the dimensions of the space of these concepts.

I have already explained why I have been driven to talk about the "space" and hence the poles and dimensions of a concept, but these are new and unfamiliar notions and I begin with some examples. In 1968 Professor Myron Wish of the University of Wisconsin showed that his students' perceptions of the relations of 12 countries of the world could be almost perfectly represented in a two dimensional space, that the poles of its first dimension were "pro-Western" and "pro-Communist" and hence its name "political alignment" and those of its second "underdeveloped" and "developed" and hence its name "level of economic development." I have myself shown that the poles of the first dimension of Kierkegaard's entire authorship are "aesthetic" and "religious" and its name "initial themes," that those of the second are "attack works" and "aesthetic and religious" and its name "whole authorship," that those of the third are "love of neighbour" and "worship of God" and its name "ends of man," etc. ${ }^{13}$ In a more recent study I have also shown that the poles of the first dimension of Fear and Trembling are "Abraham's deed" and "problems raised, especially by his silence" and its name "main themes," that those of the second are "religious" and "ethical" and its name "rival

13 McKinnon. Alastair, "Mapping the Dimensions of a Literary Corpus." Literary and Linguistic Computing. vol. 4. no. 2. 1989. pp. 73-84. 
perspectives," that those of the third are "his deed" and "his silence" and its name "justification of Abraham," that those of the fourth are (again) "religious" and "ethical" and its name "justification of his deed," etc. ${ }^{14}$ The lesson is, I think, clear. A perception, corpus, book, concept, etc., may be represented as a space having many dimensions, that together these dimensions constitute the structure of that space, that, as we shall see shortly, the name of each dimension represents what is common to the names of its two poles and that these poles are themselves defined by the nature of the chief contributors to the inertia of that dimension in the direction of these poles. Note that dimensions are not identical with the chapters or other formal divisions of a book but are rather the underlying oppositions or dialectical tensions within it. Thus chapters which are united on one dimension are frequently divided on another and vice versa.

The results of our correspondence analyses of A's and B's concepts of woman are shown in two quite different but related forms. The chief contributors to both poles of the first three dimensions of the space of each of these concepts are shown in the body of the text and include all book points contributing $3.0 \%$ or more and all word points contributing $1.0 \%$ or more of the inertia on these dimensions. The full three dimensional plots of these spaces are shown in figures 1 and 2 and their center or core in figures 3 and 4 , in both cases together with the names of the poles and dimensions as indicated by the specific nature of their chief contributors. Note that A's concept involves 241 and B's 167 separate points and that in no case was it possible to plot more than a few of the most relevant ones; indeed, with my present rather primitive graphics program I was not able to label even all of these. Note, too, that the point of origin in all these

14 McKinnon, Alastair, "The Multi-Dimensional Concordance: A New Tool for Literary Research," Computers and the Humanities, (forthcoming). 
figures is indicated by the small round point at the top of the dotted line and that the names of poles are shown in lower case and those of dimensions in full capitals, the last for the sake of the reader.

Figure 1 shows the space of A's concept of woman, most of the highest contributors (which are often also outliers) and the names of the first three dimensions and their poles which I have supplied on the basis of my knowledge of the text and of the chief contributors. Those for the first dimension are shown below together with their percentage contribution. Note that, as in all future cases, the number at the left indicates the dimension and the plus and minus signs its two poles. Thus the very first line indicates that DY ("Diary of the Seducer") contributes $22.0 \%$ of the inertia on the first dimension in the direction of its positive pole in the book version of this space and the first entry on the next that "she" contributes $5.0 \%$ of this inertia in the word version. Of course, these signs are purely arbitrary and certainly do not mean that one pole is superior or preferable to the other.

DY 22.0, TR 4.6, SH 3.6

she 5.0 , her (dep.) 2.2,her(s) (poss.) 2.0, I (l.c.) 1.9, She 1.8, me (dep.) 1.7, my (comm.) 1.1

ME 69.7

Don 9.8, Juan 8.4, seducer 2.6, the desire 2.1, Leporello 1.6, erotic love 1.5, Middle Ages 1.5, individual 1.4, the desired 1.2, Mozart 1.2, the music 1.2 , the sensuous 1.2 , namely 1.1 , the Page 1.1 , later 1.1 , constantly 1.0

I confess that the naming of this dimension has caused me some difficulty. The nature of the book contributors (chiefly, DY vs. ME) suggest that it is about the contrast between the 
calculating and the "purely sensualist" seducer and this may well be the case for this book as such as distinct from its account of woman. In fact, the author plainly says that neither Johannes nor Don Juan are seducers in any ordinary sense of that term. More to the point, four of the seven chief word contributors, indeed four of the first five, are clearly and unmistakably feminine pronouns. Plainly, then, this pole represents woman or, more precisely, woman as A and, perhaps particularly, the erotic but ineffectual Johannes imagines or wants her to be, namely, one who secretly yearns to be seduced and who flatters man's vanity by becoming herself the seductress. I have therefore named these poles seducer and seductee/seductress and the dimension itself simply SEDUCTION. Note that these names give due weight to woman, or at least to A's idea of woman, and acknowledges the role of both sexes in this clearly mutual act.

SH 39.2, TR 30.4

sorrow 10.4, Antigone 6.0, the sorrow 5.8, of sorrow 4.9 , bride 4.0 , secret 3.5 , the outer 2.9 , pain 2.4 , her(s) (poss.) 1.8, the reflection 1.8, Greek 1.6, dear 1.6, reflected (p.t.) 1.6, Symparanekromenoi 1.6, proud 1.5, reflected (p.p.) 1.4, deceiver 1.3, observation 1.3, inner 1.3 , objective 1.3 , woman's 1.3 , interest 1.1 , picture 1.0 , love 1.0

\section{DY 30.1}

being 1.8 , another 1.7 , the woman 1.4 , the man 1.3 , womanliness 1.3, Cordelia 1.1, young 1.0

The positive pole of this dimension clearly represents woman's sorrow. This is clear from the large contributions of the three forms of this word and of "Antigone" and is confirmed by those of "secret," "pain," "her(s)," "the reflection," "Greek," 
"reflected," etc. and the fact that both $\mathrm{SH}$ and TR stress the sorrowful aspects of woman's life. Similarly, the negative pole represents man's pleasure. This is clear from the fact that DY assumes that the meaning of woman's life is found in erotic love, that the woman is for the pleasure of the man or, a yet more terrible formulation, that she is "being for another." (for example, 396/424/42915) These poles represent A's view of her destiny and I have therefore named this dimension HER FATE.

$3+\quad$ TR 57.4

Antigone 14.6, bride 9.7, pain 6.7, secret 4.7, Greek (pl.) 4.0 , feels 2.7 , gives 1.4 , she 1.2

\section{SH 42.1}

sorrow 5.7 , the outer 4.1 , picture 2.5 , reflected (p.t.) 2.3 , reflected (p.p.) 2.3 , deceiver 1.8 , observation 1.8 , of, to, that 1.7 , inner 1.7 , I (l.c.) 1.7 , objective 1.8 , woman's 1.8, love 1.6, Elvira 1.0, proud 1.0

Both the book and word contributors to the positive pole of this dimension show that it represents "Greek sorrow" or sorrow as known and possibly experienced in the Greek classical world. By contrast, most of the contributors to the negative pole represent a new kind of "reflected" sorrow which this text presents as possible only after the Christianity of the Middle Ages, the precise nature of which $\mathrm{A}$ is concerned to explain and which, I confess, I do not fully understand. I therefore call this dimension simply SORROW as the factor common to both its poles. Note that this dimension thus represents a division of the positive pole of the previous dimension and, again, that such divisions and even re-combinations are common in

${ }^{15}$ HONG AND HoNG translate this expression as "being-for-another." 
correspondence analysis results.

Figure 2 shows the first three dimensions of B's concept of woman and is of course the counterpart of figure 1. The chief contributors to its first dimension are shown below.

\section{$1+\quad$ E1 18.3, M1 15.1, M2 5.3 \\ you 6.0, your (neut.) 3.1, your (comm.) 2.5, dread 2.3, you (dep.) 2.3 , moment 2.1 , will, would 2.0 , sum 1.8 , glance 1.2 , soul 1.2 , eternity 1.0}

\section{- $\quad$ E2 53.6, M3 6.4}

the man 5.9 , I 4.1 , she 4.0 , finiteness 2.4 , prayer 2.0 , explain 2.0 , the woman 1.8 , the congregation 1.7 , She 1.6 , to pray 1.5 , sits 1.5 , wife, woman 1.4 , mother 1.4 , intercessory prayer 1.3, her(s) (poss.) 1.3, game 1.3, Sunday 1.3, imperfection 1.3, man 1.2, my (comm.) 1.2 , intelligence 1.1 , the woman's 1.1 , pain 1.1

All three book contributors to the positive pole, and the first two in particular, focus mainly upon B's understanding and analysis of A's condition. This is confirmed by the strong contributions of the various forms of the second person pronoun which reflect the strong "You are the man" tone of these sections and the prominence of the words "dread," "moment" (or "instant"), "glance" and "soul." By contrast E2 challenges A's concept of woman and presents an enthusiastic account of her distinctive qualities. Bearing this in mind, and remembering the relation of these two volumes to one another, I have called these poles A's condition, her qualities and this dimension simply B'S REPLY.

$2+\quad$ M3 79.7

doubt 7.0 , the doubt 7.0 , exalt 6.8 , home 6.6 , to 
describe 5.3, the Church 4.1, lies, implies 4.1, feeling 3.3 , to grip 2.6 , love 2.6 , first 1.9 , the children 1.6 , the door 1.6 , the woman's 1.6 , the (neut.) 1.4 , hold fast 1.3 , power 1.3 , the marriage 1.3

\section{E2 16.6}

she 2.3 , my (neut.) 1.7, wife, woman 1.4, She 1.3, her(s) (poss.) 1.3, you (dep.) 1.2

M3 contains B's attack upon the doubt of the age and its effect upon society and this is reflected in the chief word contributors to the positive pole. For example, that doubt is said to represent a threat to "home," "love," "the children" and "the marriage." The age "exalts" doubt as if the chief aim of life were to destroy everything (92/96/95) and A rejects aspects of the teaching of "the Church" on woman which are beyond possible doubt. (89/93/91) I have therefore called this pole the "ages's doubt." By contrast, E2 stresses the socially redemptive power of woman's special qualities and many of the uses of feminine pronouns in this part of the text refer to woman as the possessor of these powers. I have therefore called this pole "her redeeming powers" and, underscoring what is common to these poles, this dimension SOCIAL FABRIC.

$3+$ E1 65.3, M3 3.0

dread 11.0, sum 9.9, glance 5.7, the spirit 5.6, smile 4.1 , to give birth to 3.7 , the (neut.) 2.9 , dares, ventures 1.9 , will, would 1.8 , soul 1.5 , home 1.2 , grasps 1.1

- $\quad$ M1 28.4

now 3.4 , love 1.8 , the sensuous 1.8 , enjoyment 1.7 , five 1.6 , very 1.5 , romantic 1.5 , harmful 1.5 , melancholy 1.5 , partly 1.2 , you 1.0 , to remember 1.0 
The third dimension provides a more detailed analysis of A's condition already encountered as the positive pole of the first. The main contributors to the positive pole of the third stress dread and those to the negative melancholy and I have therefore called these poles dread and melancholy and the dimension itself A'S CONDITION. Note, however, that many of the contributors to these poles involve a reference to one or more women. B compares A to the Roman emperor Nero whose life was also one of "dread," who is terrified of "the spirit," whose "glance" can mean death and whose "smile" can be fatal (175/191/187), but he also compares him to a woman who fears she may give birth to a monster (192/210/206) and, reminding him of Tarquin, advises him to buy the old widow's remaining books for the original "sum" before she burns the rest. (194/213/209) So, too, with the chief contributors to the negative pole. Ml stresses A's melancholy (B's earlier diagnosis) but many of the contributors to this pole are connected with woman. Because of his melancholy A makes "enjoyment" the chief thing in his life (28/25/24) and, as we have seen, enjoys himself "now" this way and "now" that $(28 / 25 / 24)$ and even experiments with the old woman from the work house by giving her "five" dollars simply for the enjoyment of watching her reaction. (17/12/12-13) His melancholy is the source of his preoccupation with "romantic" "love" and "the sensuous" (25/21/21) and, while a less extreme form might be acceptable in others, it is "very" "harmful" to A and B advises him to abandon it immediately. (17/11/11) Of course it is not surprising that this further analysis of A's condition contains many references to woman since B regards his condition as the cause of his inability to have any meaningful and lasting relation with woman and woman as his best hope of a cure of his illnesses.

We pause for a moment to summarize our results to date. Briefly, these show that A and B hold very different concepts of 
woman. A conceives her primarily as an erotic or, as we might now say, sexual object. In his imagination she is simply an object for erotic experimentation, the meaning of whose life is simply to give man pleasure and who is ultimately condemned to sorrow of a peculiar and particularly modern kind. By contrast, B conceives her as "a being" with quite distinctive qualities which have redeeming powers to knit together the social fabric, undo the damage done by the age's doubt and even cure A's illnesses. All this and, indeed, much more is implied by the words unique to their respective aberrant frequency word lists and their two quite different spaces already described.

Figure 3 shows an enlargement of the central area of the space of A's concept together with the two book and 18 word points closest to its center and, of course, the same poles and dimensions as figure 1. There is not time to explain all the coordinates of these points nor all the ways in which they confirm our names for these dimensions but we note that PD lies primarily in the direction of the negative pole of the second dimension because most of its relatively few aberrant frequency words are associated with man's pleasure and DY mainly in that of the positive pole of the first because most of its words are connected with the phantom seductee/seductress figure. We also cite below references to uses of these words which illustrate why they lie primarily or mainly in some particular area of this space. Thus 142/151/153 shows why "she" lies primarily in the direction of the positive pole of the first dimension. Note that this information is quite different from and not to be confused with that concerning chief contributors given above.

$\begin{aligned} 1+\quad & \text { she } 142 / 151 / 153, \text { I (u.c.) } 142 / 151 / 153, \text { me (dep.) } \\ & 141 / 151 / 153, \text { I (1.c.) } 142 / 151 / 153 \\ & \text { significance } 58 / 57 / 58, \text { resistance } 85 / 87 / 89 \text {, woman } \\ & 73 / 75 / 76\end{aligned}$


$2+$ moves $161 / 172 / 173$

modesty 314/335/339, sexual union 409/438/443-4, the erotic $353 / 377 / 382$, the infinite $361 / 386 / 391$, girl $314 / 335 / 339$

$3+$ aesthetic $146 / 155 / 158$, nature $396 / 425 / 430$, in general $312 / 333 / 337$

- $\quad$ lover $321 / 342 / 346$, the hand $160 / 171 / 173$

Note that even these relatively central points lie primarily in those areas of this space which our account leads us to expect and that this is further and important evidence that this space is ordered and coherent even at its core.

Figure 4 shows an enlargement of the central area of the space of B's concept together with the two book and 18 word points closest to its center and, again, those of its poles and dimensions. Note that M1 tends mainly in the direction of the negative pole of the third dimension because, as already noted, it deals with A's melancholy and M2 mainly though only slightly in that of the positive pole of the first because it deals more generally with A's condition. As in the previous case, we also cite references illustrating why these words lie primarily in one or more particular directions in this space.

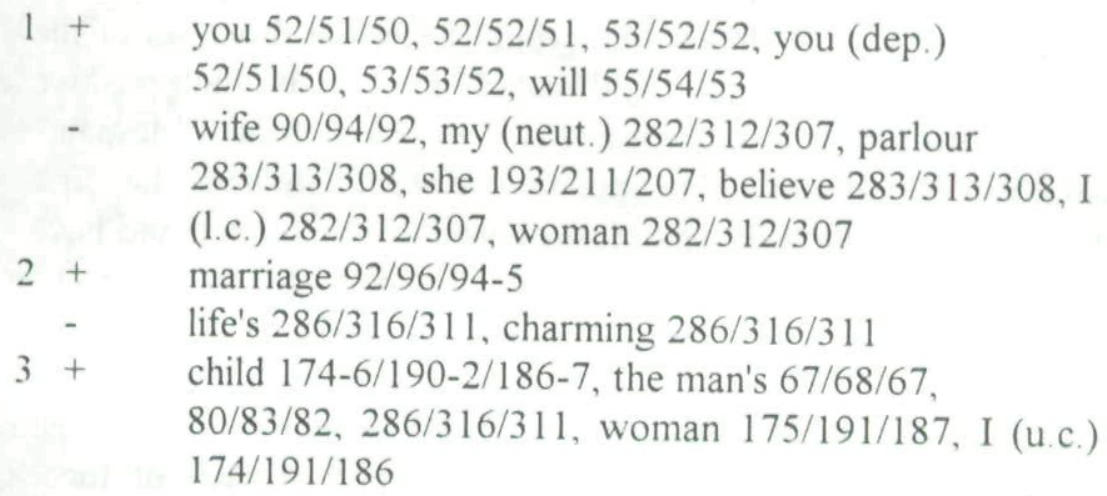


- $\quad$ beauty $15 / 9 / 9$. children $66 / 67 / 66$

Note that these relatively central points also lie where our dimensions prompt us to expect them and that this too is further and important evidence that this space also is ordered and coherent even at its core.

We have just seen that in the case of both these spaces it is possible to explain the positions of the central points in terms of dimensions the names of which have been derived in most cases from outlying ones. This means that within each of these spaces there is a common structure which, almost certainly, is that of the texts from which they are derived. It also means that the names of our dimensions describe and capture these structures at least more or less accurately.

This same important point is also demonstrated by two small experiments which I mention in passing. Having noted that "destiny" [Bestemmelse] had just missed the aberrant frequency list for A and "despair" [Fortvivlelse] that for B I decided to rerun each of these sets with these words as supplementary points, i.e. points to which the program assigns co-ordinates within the existing space or structure but without allowing them to alter it in any way. In fact, given the meaning, role and distribution of these terms, I predicted that "destiny" would have a high positive coordinate on the first dimension, would lie in the direction of the positive pole on the second and would have a quite high positive co-ordinate on the third. Similarly I predicted that "despair" would have a very high positive co-ordinate on the first dimension, would be more or less neutral on the second and have a very high positive co-ordinate on the third. In fact, the coordinates for "destiny" were $0.443,0.343$ and 1.061 and those for "despair" $1.426,-0.420$ and 2.324 . In short, I was able to predict all but the second coordinate of "despair" more or less accurately. This is further strong evidence that each of these 
spaces is coherent and integral and accurately mirrors the structure of the text as expressed by our dimensions. Of course it does not necessarily mean that they have captured the text "as it really is" (perhaps only God can do that) but the ability to predict so successfully is the best evidence humans can have that they are at least on the right track and, in this case, that this space at least closely approximates the structure of the text.

You have perhaps suffered long enough, and I conclude with a simple result which may serve to focus thought and discussion. Having created the space of A's and B's concept of woman using the 10 principal forms of that word I now show the 20 words (nouns, verbs, adjectives and adverbs) closest to the form "woman" $[$ Qvinde $]$ within each of these spaces. Those who already know the typical uses and contexts of these words will see their significance immediately and those prepared to investigate them will learn a great deal about the differences between these two concepts.

$\begin{array}{ll}\text { The A List } & \text { The B List } \\ \text { lay [within] } & \text { the man's } \\ \text { significance } & \text { dignity } \\ \text { single } & \text { the woman, wife } \\ \text { hears } & \text { parlour } \\ \text { real, essential } & \text { believe } \\ \text { generally } & \text { child } \\ \text { Greek } & \text { man } \\ \text { aesthetic } & \text { husband } \\ \text { almost } & \text { wife } \\ \text { move } & \text { children } \\ \text { independently } & \text { to marry } \\ \text { resistance } & \text { intelligence } \\ \text { appears } & \text { religious }\end{array}$


idea

essentially

is brought

bearing

the gods

girl

attracted a being

pain

significance

the woman's

humble

the marriage

almost

The words "significance" and "almost" appear in both but it is clear that these lists come from and represent two quite different views of woman. A presents her in the context of his broad and sweeping historical and cultural generalizations, but beneath this facade sees her in fundamentally aesthetic and erotic terms. The significance of her life is to provide pleasure for man, either immediately in physical love or, perhaps preferably, as an object of his imagination and fantasy. It is then not surprising that, as we have already seen, he writes at length of womanliness or femininity. By contrast, B presents woman in the concrete and immediate context of marriage, children, the home, society and religion. She has her own distinctive nature and is at once "more perfect and more imperfect" than man. She gives dignity to life, "explains" the meaning of time and her domestic activity reveals life's deepest meaning and expresses the importance of action in marriage. Note that these differences, which could of course be expanded and developed much more fully, have all come from the simplest glance at one small area of the spaces generated and discussed in this study.

I believe and trust that the conclusions reached in this study are true and helpful but, hoping that others may use this method on some problem of their own choosing, add two recommendations. If possible, one should divide the extracted text according to the chapter or other divisions in the original or, failing that, make a real effort to find the real divisions within 
those chapters and texts with particular regard to the subject under investigation. I also recommend that, where possible, one use sentences rather than paragraphs as the context unit for the search word or words. As already explained, the use of the paragraph was necessary and justified in this particular study but it is often too large and is generally to be avoided.

The discovery of such very different views of woman within one of Kierkegaard's books suggests a comparison of these views with those of some other influential figures of the recent past. For example, it is clear that Freud saw sex only as eros and woman as simply a defective copy of man; indeed, his views on both these subjects are almost as thin and hysterical as those of A. Kierkegaard, at least in the person of B, provides much richer and more fruitful concepts of both. He sees woman as a different and autonomous version of humanity and so is able to recognize and celebrate both her possible contribution to the re-shaping of humanity and the nature, depth and importance of what for Freud are merely physical and bodily relations.

Marx fares no better. He emerges as a parochial thinker completely bewitched by the fact that at a certain point in time a small group of persons used their control of capital to acquire an inordinate and totally unacceptable amount of power over the vast majority of their fellows. By contrast, Kierkegaard is a truly radical thinker who sees that the real problems of our society and culture are due to the fact that they have been shaped and are now controlled by what is at best one of two very different and equally ambiguous versions or halves of humanity. In a word, Marx explains the abuse of power in terms of history and Kierkegaard in terms of our nature. Put another way, Marx explains the mechanism of capitalist society while Kierkegaard points instead to its underlying motivation.

The comparison with Marx is equally favourable. The latter is an essentially shallow thinker completely bewitched by the fact 
that a small group of persons have quite by chance acquired an inordinate and totally unacceptable amount of power and control over the vast majority of their fellows. By contrast, Kierkegaard is a truly radical thinker who sees that the real problems of society are due to the fact that it has been shaped and is now controlled by what is nothing more than one of two very different and equally ambiguous versions or halves of humanity. In a word, Marx's explanation of the abuse of power is in terms of history and Kierkegaard's in terms of nature. For many years I have thought that Marx's account of history was extremely superficial and note that Kierkegaard's view of woman shows why and how this is so.

Any comparison of Kierkegaard with contemporary femininists must begin by distinguishing their two kinds. Some still imagine that the differences between the sexes are merely physical and that the goal therefore should be to attain equality in what essentially is, though of course they do not know it, merely a man's world. Other more enlightened members of the movement grasp the truly radical character of human sexualization and seek nothing less than the total rewriting of values to give due weight to woman's distinctive nature and insights. The former, whom I call patriarchal feminists, tend to dismiss Kierkegaard as a hopeless reactionary on the basis of views expressed by $\mathrm{A}$ and elsewhere in his writings. The latter have already seen through the patriarchal mythology but many of them could, I think, still learn a great deal from B. Certainly his work deserves their careful reading and reflection.

I conclude with one final observation. A twice mentions Plato's references to the myths of a pre-sexual or androgynous humanity (385/412/417-8 and 409/438/443-4) but clearly does not understand their importance and, so far from being helped, is only suspiciously excited by them. By contrast, B apparently knows nothing of them but has clearly grasped their deeper 
significance. A claims and is supposed to be the master of the aesthetic but I believe that B has shown that he has a much deeper understanding of its true nature. Their relations to these myths suggests another such difference. B has always had a bad press as a dull and plodding fellow but in fact he lets these myths inform his life and understanding without even knowing of their existence. This suggests to me at least that he, not $\mathrm{A}$, is also the real master of imagination. 


\section{Table 1. Words strongly associated with woman in A and B}

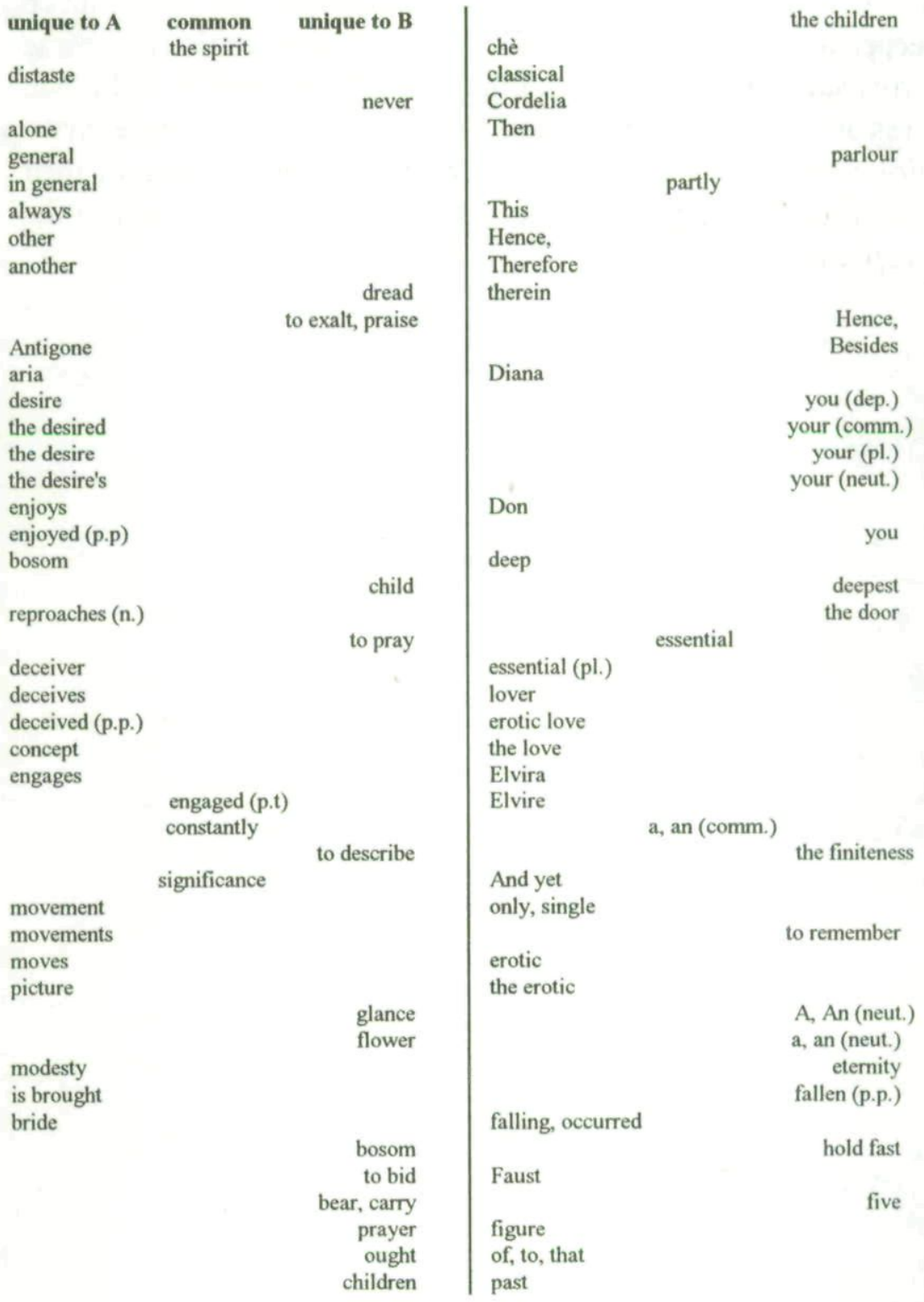


obtains, takes place

sexual union

seduction

seducer

seduces

disturbingly

free

suitor

courts

joy

is born

feels

gives

more perfect

found (p.p.)

to give birth to

feeling

first

times marry (imp.)

to marry

marries

delights (v.)

well, good

to grip

grasps

Greek culture

Greek

Greek (pl.)

the gods

the hand

have

all

secret

Her(s) (poss.)

her (dep.)

her(s) (poss.)

devote, give oneself to

In this respect

here

herein, in this

of the Lord

of this, for this

home
In the case of

in the case of

She

intelligence

she

wife

rest (n.)

rested (p.t.)

for which

happens

high, worthy

hears

observation

idea

the idea

As

as

Not

However

however

against

into

individual

inner

interesting

the

interesting

interest

expression

I (u.c.)

I (I.c.)

virginity, girlishness

Juan

Juan's

casts (v.)

the church

dear

cold

the love

wife,woman

power

game

Leporello

light, easy

easy, relieved

lies, implies

just as, equally

Listen

life's

bearing, posture

happy 
listens

lips

More

Middle Ages

$$
\begin{gathered}
\text { me (dep.) } \\
\text { my (comm.) }
\end{gathered}
$$$$
\text { my (neut.) }
$$$$
\text { mother }
$$

resistance

opposition

Molière

moments

the moment

Mozart

music

the music

mythical

nature

the nature

namely

Now

enjoys

objective

Also, As

well

the opera

attention

above

on, upon

Page

the Page

brow

girl

girls

girl's

enjoyment

near, almost

often, frequently woman

womanly

womanly (pl.)

womanliness

the womanliness

of womanliness

the woman

the woman's

women

woman's

bright

reflected (p.t.)

reflected (p.p.)

reflection

the reflection

speech

rich

blush

religious

romantic

such

conscience

sensuous

the

sensuous

sensuous (pl.)

the sensuousness

of sensuousness

the scene

victory

companion

later

side, phase

the side

psychical (pl.)

harmful

beautiful

Although

beauty

more beautiful

most beautiful

right, beautiful

school

step

such things

pain

smile 


sorrow
the sorrow
of sorrow
leap
stage
moods
the path
proud
pride
the play
stronger
the sum
visibly
the lake
of thought
the aunt
in common
belongs
belonged (p.p.)
run
be present (v.)

to think, imagine expressed (p.p.)

the outer

the infinite

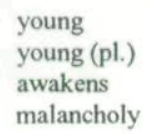

suggestion

effect

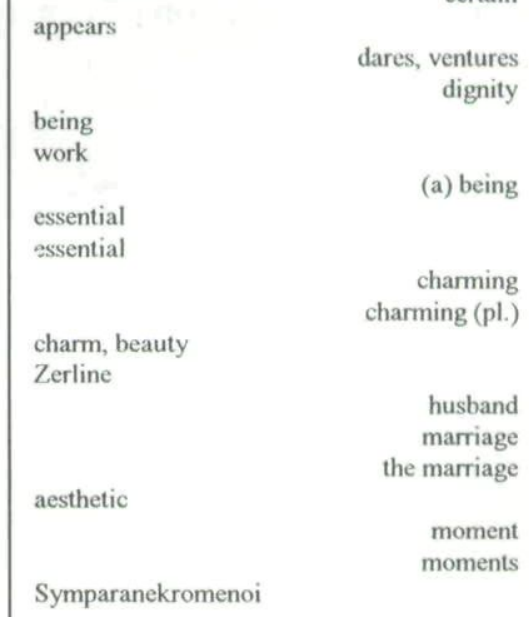

$\begin{array}{lr}\text { aesthetic } & \begin{array}{r}\text { moment } \\ \text { moments }\end{array} \\ \text { Symparanekromenoi } & \end{array}$

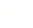

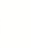

\section{5 words unique to $A$ 130 words unique to $\mathrm{B}$ \\ 31 words common to $\mathrm{A}$ and $\mathrm{B}$}
Percent common $=$ $8.740 \%$
Index/Concordance $=\quad 0.124$


Figure 1. A's conception of woman; some major contributors and outliers.

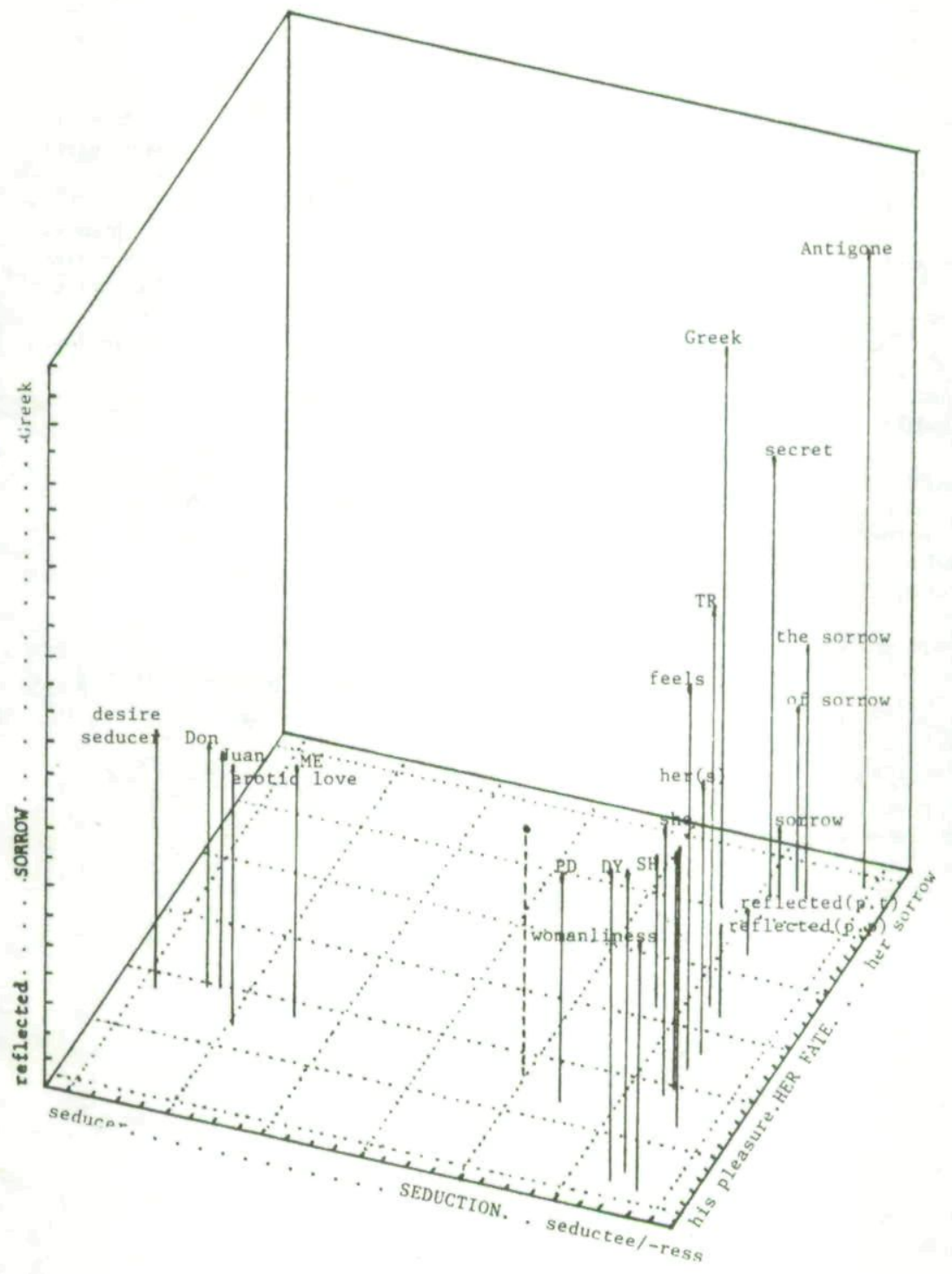


Figure 2. B's conception of woman; some major contributors and outliers.

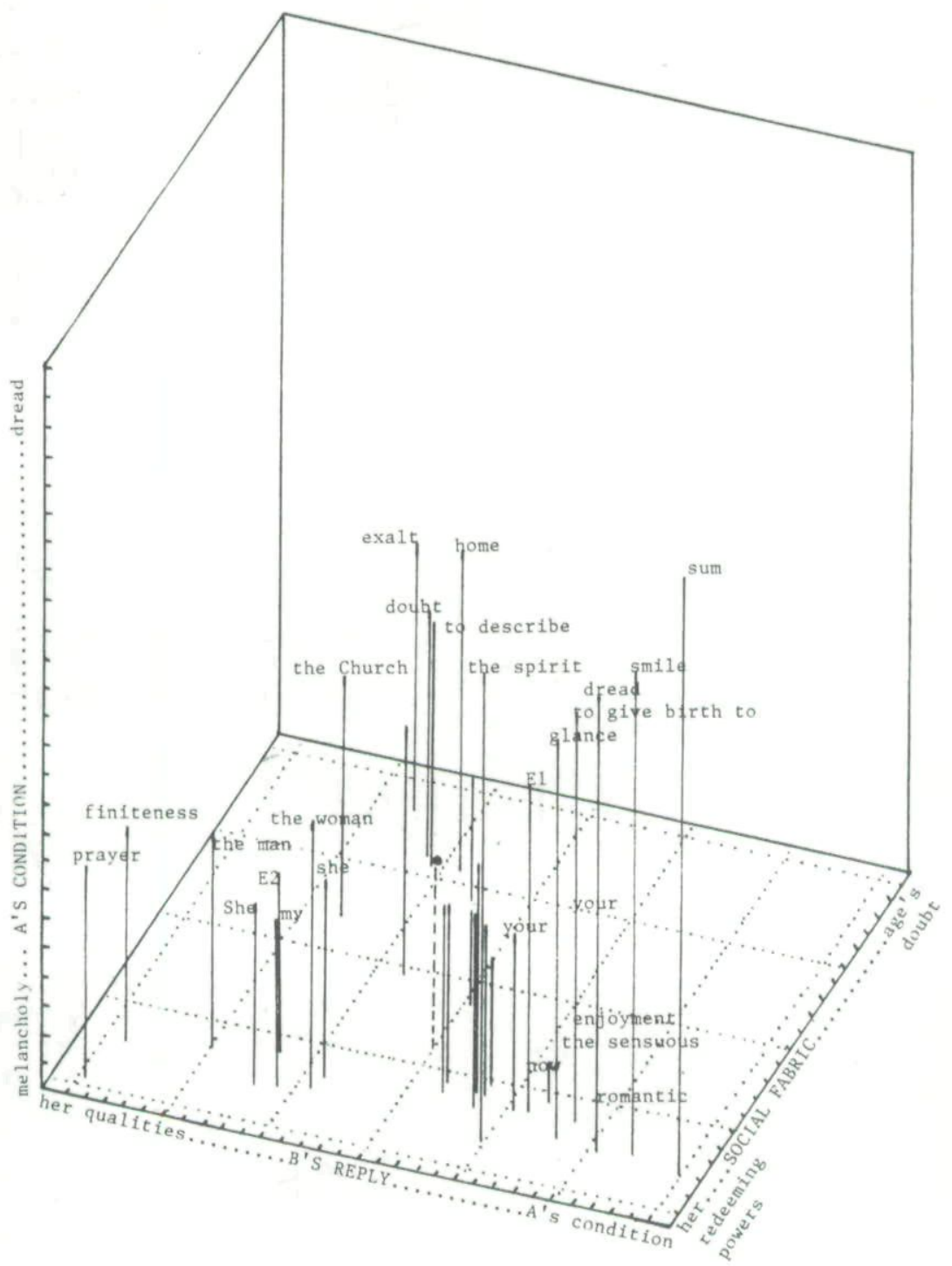


Figure 3. A's conception of woman; some central or core points.

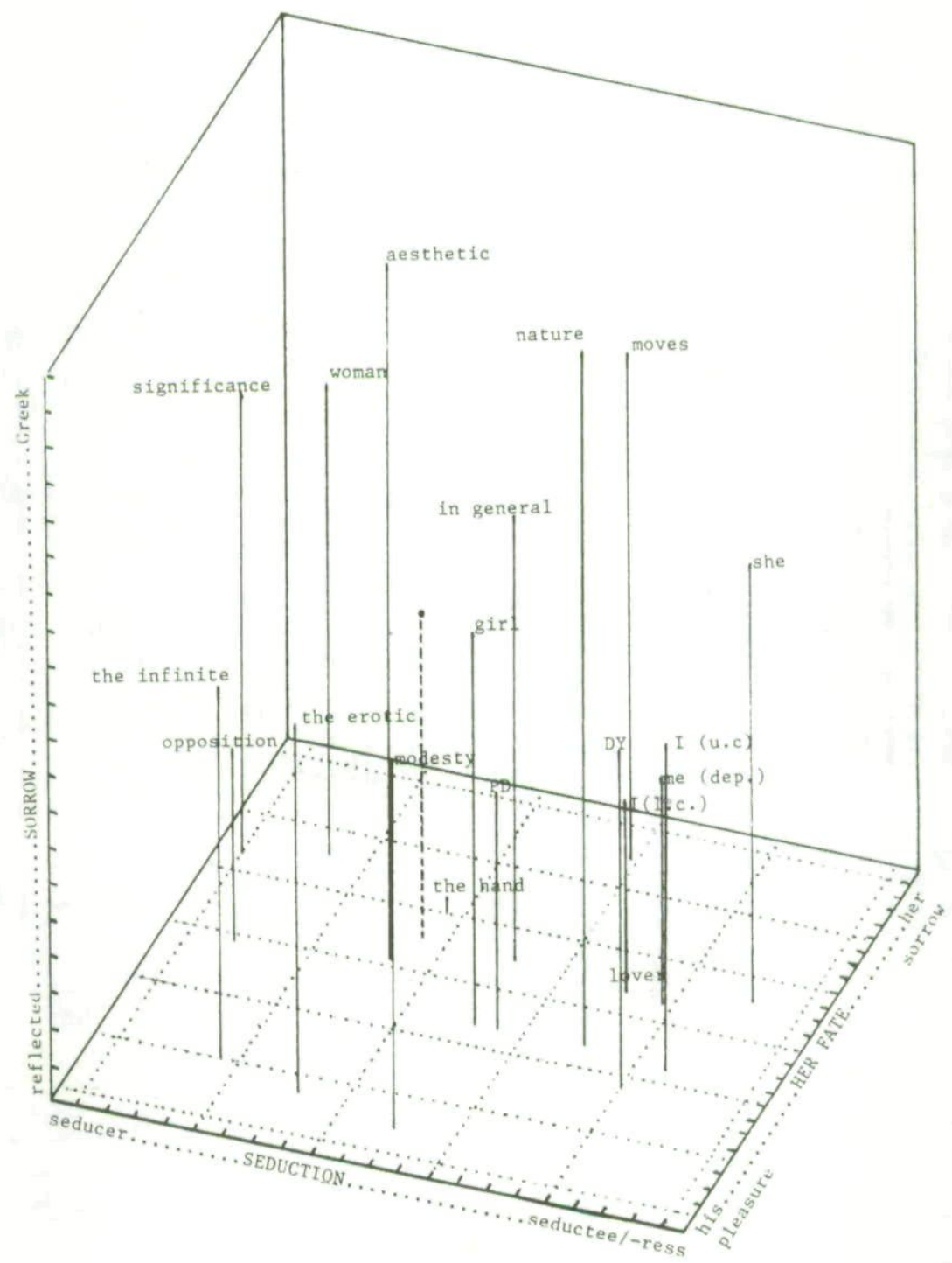


Figure 4. B's conception of woman; some central or core points.

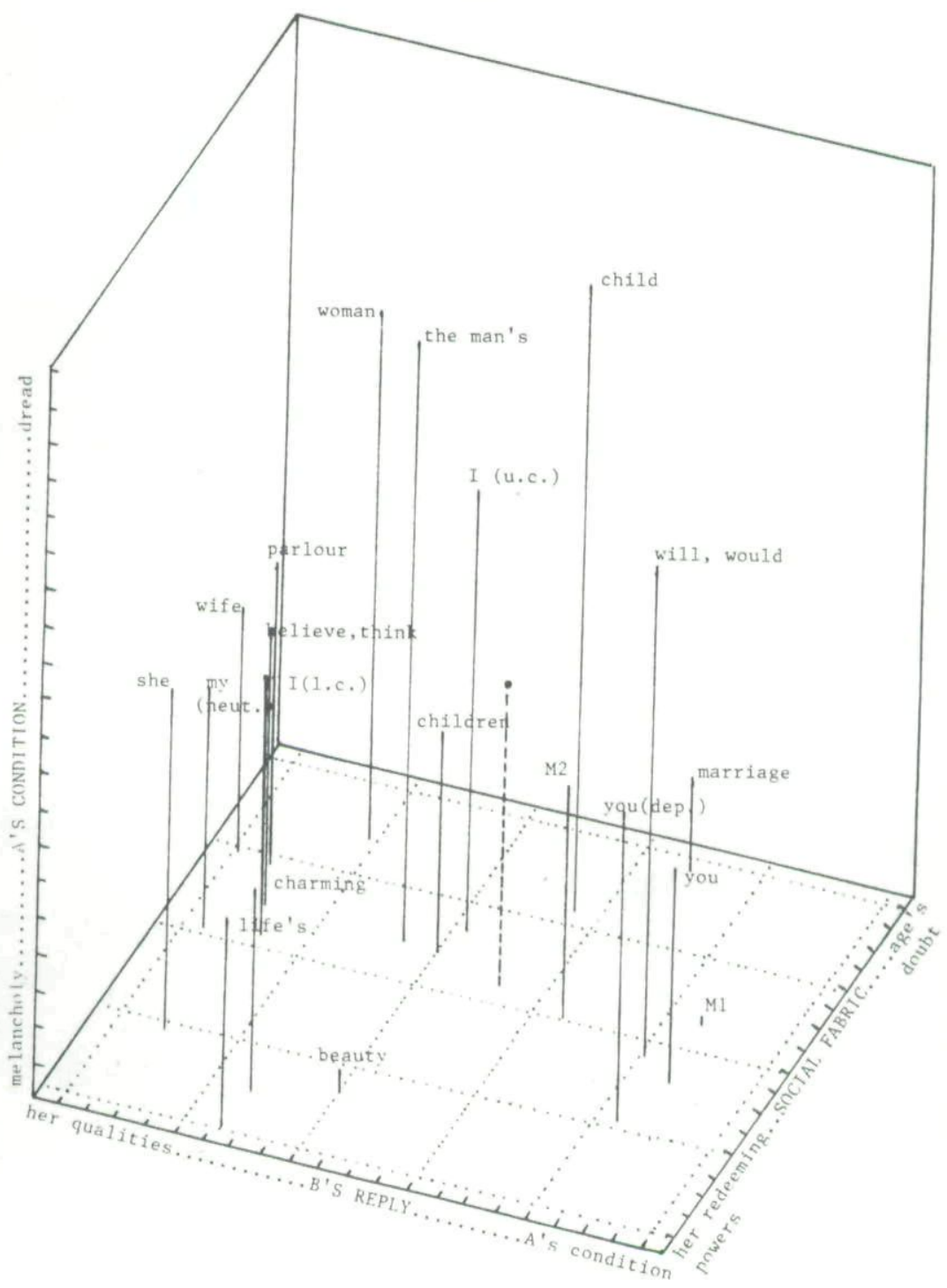


Copyright of Tópicos. Revista de Filosofía is the property of Universidad Panamericana and its content may not be copied or emailed to multiple sites or posted to a listserv without the copyright holder's express written permission. However, users may print, download, or email articles for individual use. 